Kindler, S. H., MAger, J. \& Grossowicz, N. (1956). J. gen. Microbiol. 15, 394-403

\title{
Toxin Production by Clostridium parabotulinum Type A
}

\author{
BY S. H. KINDLER AND J. MAGER* \\ Israeli Institute for Biological Research, Ness Ziona, Israel \\ AND N. GROSSOWICZ \\ Department of Bacteriology, the Hebrew University-Hadassah Medical School, \\ Jerusalem, Israel
}

SUMMARY : Factors which govern toxin production by Clostridium parabotulinum type $\mathbf{A}$ were studied in growing cultures and in non-proliferating cell suspensions. With growing cultures high toxin titres, comparable to those obtained in complex media, were obtained in a defined medium containing the following essential constituents: arginine, cysteine, histidine, isoleucine, leucine, methionine, phenylalanine, serine (or glycine), tyrosine, tryptophan, valine, glucose, vitamins, phosphate and magnesium. Most of the toxin was formed only after cessation of growth.

Resting suspensions of organisms produced toxin at a rapid rate; a three-to fivefold increase being obtained after $4 \mathrm{hr}$. incubation. It appears that the toxin is synthesized within the organisms and is liberated into the medium by autolysis. Release of toxin on artificial lysis by sonic oscillation, provided decisive evidence for this conclusion.

The effect of different metabolic inhibitors on toxin synthesis by resting organism suspensions was examined. Ethylenediamine tetracetic acid in amounts which did not inhibit growth suppressed completely toxin production. Some broad spectrum antibiotics (streptomycin, chloramphenicol, chlorotetracycline at $100 \mu \mathrm{g} . / \mathrm{ml}$.) inhibited toxin formation to about 50\%. Penicillin did not affect toxin synthesis even at concentrations 1000 -fold higher than those required to arrest growth of the organism.

The production of toxin by Clostriaium parabotulinum type A has been studied hitherto in complex empirical media (Lewis \& Hill, 1947; Stevenson, Helson \& Reed, 1947). These studies revealed the importance of some factors which govern the accurnulation of the toxic protein in the culture fluid; these included nutrients, temperature, $\mathrm{pH}$ value, and period of incubation. However, in view of the complexity of the media used, the chemical nature of the components required for toxin production could not be exactly determined. Following the development of a defined medium for the cultivation of C.parabotulinum type A (Mager, Kindler \& Grossowicz, 1954), it became possible to study the production of toxin under defined conditions. The present communication describes toxin formation by proliferating cuitures, and by resting organism suspensions, in defined media. 'T'he latter system permits a distinction between the requirements for multiplication and the factors which affect more directly toxin formation. The site of toxin synthesis (Nelson, 1927; Dack \& Wood, 1928; Raynaud \& Second, 1949), was also studied. A brief report has already been published (Kindler, Mager \& Grossowicz, 1955).

* Present address: Department of Biochemistry, the Hebrew University-Hadassah Medical School, Jerusalem. 


\section{METHODS}

The general procedure, experimental conditions and the composition of the defined and partially defined media were described previously (Mager et al. 1954). Most experiments were performed with strains no. 1 (Hall, NCTC 3811) and no. 2 (Hebrew University, Jerusalem) of Clostridium parabotulinum type A. Stock cultures were kept in cooked meat broth. For the purpose of studying toxin production the organism was carried through several subcultures in the casein hydrolysate partially defined medium (CH., see legend to Table 1 ). This partially defined medium (10 ml.) was inoculated with $0.1 \mathrm{ml}$. of an $18-24 \mathrm{hr}$. culture.

Composition of the complex (CCG) medium (in \%): Casein, 3; cornsteep liquor solids, 1 ; glucose, $0 \cdot 5$.

Non-proliferating organisms were prepared as follows: after $18 \mathrm{hr}$. growth in the casein hydrolysate partially-defined medium the organisms were collected by centrifugation (Servall centrifuge, 6000 r.p.m.) for $15-20 \mathrm{~min}$. and washed with saline containing $0.05 \%$ mercaptoacetate, or with fresh medium as desired. The organisms were then resuspended in media of various compositions and incubated at $34^{\circ}$ under anaerobic conditions.

Extraction of toxin from the organisms. Clostridium parabotulinum organisms were disintegrated by sonic oscillations by means of a Raytheon 9 KC Oscillator. The apparatus was cooled by circulating ice-cold water. Exposure of suspensions ( 2 to $6 \times 10^{9} \mathrm{organisms} / \mathrm{ml}$.) for $15 \mathrm{~min}$. to sonic vibrations resulted in destruction of most of the organisms (as revealed by decrease of turbidity and by microscopic examination). As shown by recovery experiments the titre of toxin filtrates, subjected to this treatment, remained practically unchanged.

Determination of toxin titre. Assays of toxin titre were carried out on white mice of $18-24 \mathrm{~g}$. body weight by injecting intraperitoneally $0.5 \mathrm{ml}$. of toxin sample suitably diluted in a buffered gelatin medium (Lewis \& Hill, 1947). The animals were kept at $28^{\circ}$, and the deaths recorded up to 4 days. The results were expressed in terms of MLD (minimal lethal dose) or LD 50 (Reed \& Muench, 1938)/ml. of toxin sample.

\section{RESULTS}

Previously we (Mager et al. 1954) reported that toxin of relatively low titre (c. 50,000 LD 50 doses/ml.) was obtained when Clostridium parabotulinum type A was grown in a defined medium. Subsequent experiments corroborated these results and also showed that on continued incubation in the defined medium the titre of the toxin declined much more rapidly than in complex culture media (Fig. 1). Since the amount of growth was about the same in the various media tested it seemed that the CCG medium provided factors which enhanced the formation of the toxin as well as its stability. A search for such factors was therefore conducted. As a first step, mixtures of various metabolites were added to the defined medium (e.g. nucleic acids and their components, vitamins of the $\mathbf{B}$ group, and members of the tricarboxylic acid cycle); 
however, no increase of toxin titre was observed. Subsequently two important components of the complex medium, namely casein and cornsteep liquor (CSL) were added together or separately. The experiments showed that both ingredients increased the titre of the toxin, but most of the activity was due to the casein. In order to determine whether casein itself or some accompanying contaminant was responsible for the enhancement of toxin formation, purified casein (obtained by repeated precipitations with acetic acid and washing with ethanol and ether) was tested. As can be seen from Table 1, purified casein when added to the defined medium showed the same activity as commercial casein. Moreover, other proteins exhibited a similar effect. The question then arose whether degradation products would be as effective as the intact protein. Subsequent tests showed that addition to the defined medium of enzymic hydrolysates of casein or commercial peptones were effective in increasing the toxin titre, but did not prevent significantly the deterioration of the toxin formed. A similar effect was obtained by increasing the amino acid concentration of the medium (Table 1).

Table 1. Effect of protein, protein hydrolysates and amino acids on the titre of botulinum toxin produced in various media mixtures

Organism: Clostridium parabotulinum type A strain No. 2.

Media: CCG medium (in \%): casein, 3.0; comsteep liquor solids, 1.0; glucose, $0 \cdot 5$. CH medium (mg./10 ml.): Casamino acids vitamin-free (Difco), 50; L-tryptophan, 0.05; Larginine, 30: DL-phenylalanine, 20; L-tyrosine, 2.5; Na-mercaptoacetate 5; salts A, B (Snell et al. 1937) $0.1 \mathrm{ml}$. and $0.01 \mathrm{ml} . / 10 \mathrm{ml}$. respectively. The following substances were Seitz-filtered and added aseptically to the autoclaved medium (per $10 \mathrm{ml}$.): glucose, $50 \mathrm{mg}$.; L-cysteine, $2.5 \mathrm{mg}$.; $\mathrm{NaHCO}_{3}, 2 \mathrm{mg}$; biotin, 0.005 $\mu \mathrm{g}$; thiamine, $4 \mu \mathrm{g}$.; $p$-aminobenzoic acid, $0 \cdot 1 \mu \mathrm{g}$.

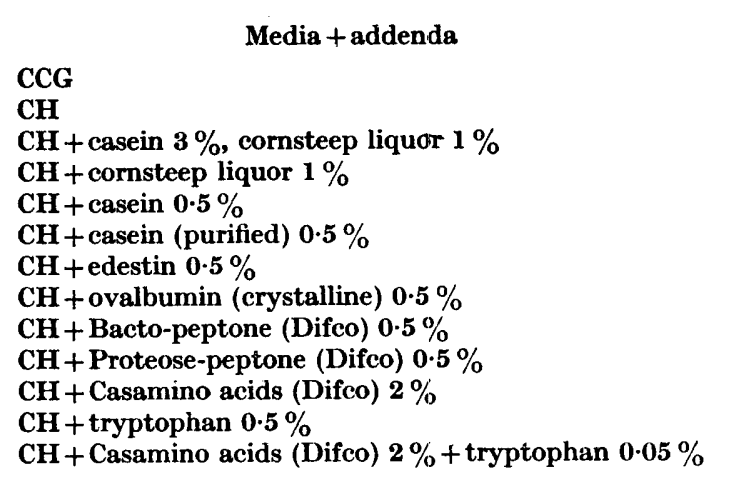

LD 50 dose/ml. after growth for

Since tryptophan was present only in small arnounts in the defined medium, it was suspected of being the limiting factor. In fact, increasing the concentration of trytpophan (from 5 to $500 \mu \mathrm{g} . / \mathrm{ml}$.) resulted in a considerable increase of the toxin yield when tested after $2-3$ days of incubation; on further incubation, however, a rapid decline of the toxin titre was observed (Fig. 1). Addition of protein to the tryptophan-enriched medium increased the stability of the toxin produced. The stabilizing effect of protein on the botulinum toxin was tested by incubation for $\mathbf{3}$ days of samples containing measured amounts of 
crude toxin in the presence and in the absence of casein. The results, as presented in Table 2 , show clearly the protective effect of the protein. Thus, at least two effects of protein were demonstrated: $(a)$ increase of toxin formation, an effect which could be duplicated by increasing the concentration of tryptophan; $(b)$ protection from deterioration (spontaneous) afforded by proteins but not by amino acids.

Table 2. Influence of proteins on stability of botulinum toxin solutions

\begin{tabular}{|c|c|c|}
\hline & $\begin{array}{l}\text { Toxin titre } \\
\text { initial }\end{array}$ & $\begin{array}{c}\text { LD } 50 / \mathrm{ml} \text {. after } \\
3 \text { days of } \\
\text { incubation } \\
\text { at } 3^{\circ}\end{array}$ \\
\hline Crude toxin preparation* & $1,500,000$ & 600,000 \\
\hline Crude toxin preparation + gelatin $0.5 \%$ & $1,500,000$ & $1,000,000$ \\
\hline Crude toxin preparation + casein $0.5 \%$ & $1,500,000$ & $1,300,000$ \\
\hline 72 hr. culture $\dagger$ & 750,000 & 200,000 \\
\hline $\begin{array}{l}72 \mathrm{hr} \text {. culture + casein }(0.5 \%) \text { added after incubation } \\
\text { for } 24 \mathrm{hr} \text {. }\end{array}$ & 800,000 & 700,000 \\
\hline
\end{tabular}

Resting organisms. When Clostridium parabotulinum organisms are sown into a suitable medium, growth is characterized by a peak reached after 18-24 hr. of incubation, which is then followed by rapid decline and autolysis. Assays revealed small amounts of toxin during the logarithmic phase of growth; thereafter the titre increased rather steeply, reaching the maximum at the completion of lysis (Fig. 1). This sequence suggested that the toxin was apparently formed when stationary conditions prevail in the culture and multiplication therefore may not be an essential factor, and that toxin was released into the medium as a result of autolysis.

In order to study toxin production in the absence of multiplication, the technique of non-proliferating organisms was used (see Methods). Under these conditions the resting organisms, which were resuspended in the complete defined medium and incubated for $24 \mathrm{hr}$., formed large amounts of toxin. The toxin formed was proportional, within limits, to the density of the suspensions used (Fig. 2). Aerobic conditions were not detrimental to toxin formation by resting suspensions; practically the same yields of toxin were obtained under aerobic or anaerobic conditions.

In order to evaluate the importance of the various ingredients of the medium for toxin formation by non-proliferating organisms, the effect of omission of different components was tested. As shown in Table 3, the omission from the complete medium of either salts $\mathrm{B}$, vitamins, or non-essential amino acids did not appreciably affect toxin formation. On the other hand, elimination of glucose, inorganic phosphates (salts $\mathrm{A}$ ) or even one of the amino acids essential for growth (e.g. arginine) decreased the titre considerably. Especially interesting seemed the requirement for glucose. Non-proliferating organisms produced very little, if any, toxin when glucose was omitted from the medium. In growing cultures, omission of glucose resulted in about a ten-fold decrease in 
toxin titre, while growth in the absence of glucose was decreased only by $50 \%$ (Table 3).

Site and kinetics of toxin production. In non-proliferating organism suspensions, as in growing cultures, only small amounts of toxin were demon-

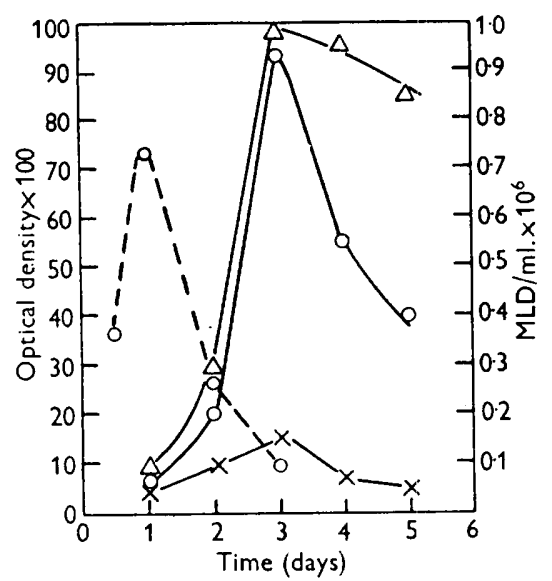

Fig. 1

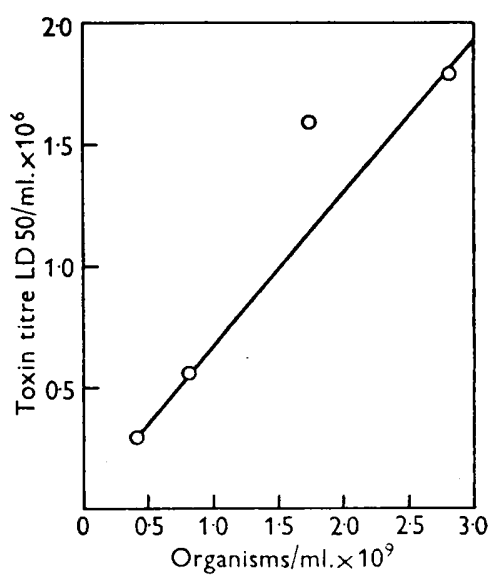

Fig. 2

Fig. 1. Growth and accumulation of toxin in various media. Clostridium parabotulinum type A (strain no. 1). $\mathrm{O}_{---} \mathrm{O}$, growth in defined medium; tryptophan $5 \mu \mathrm{g} . / \mathrm{ml}$. $x \longrightarrow x$, toxin formation in defined medium; tryptophan $5 \mu \mathrm{g} . / \mathrm{ml}$. $\mathrm{O}-\mathrm{O}$, toxin formation in defined medium; tryptophan $500 \mu \mathrm{g} . / \mathrm{ml} . \triangle-\triangle$, toxin formation in defined medium + casein $0.5 \%$.

Fig. 2. Toxin titre as a function of cell density. Clostridium parabotulinum type A, strain no. 1. Incubation time $17 \mathrm{hr}$. at $34^{\circ}$.

Table 3. Effect of various nutrients on toxin production by non-proliferating suspensions of Clostridium parabotulinum type A, strain no. 2

Incubation time: $24 \mathrm{hr}$. at $34^{\circ}$. Composition of incubation mixture $(\mathrm{mg} . / 10 \mathrm{ml}$.): $\mathrm{DL}-$ alanine, 5; DL-aspartic acid, 9 ; L-arginine, 30 ; L-cysteine, 2.5 ; DL-glutamic acid, 10 ; glycine, 10 ; L-histidine, 2; L-hydroxyproline, 1 ; DL-isoleucine, 5 ; DL-leucine, 15; L-lysine, 10 ; DLmethionine, 6; DL-phenylalanine, 20; L-proline, 4.5; DL-serine, 10; DL-threonine, 10; L-tryptophan, 5; L-tyrosine, 2.5; DL-valine, 20; glucose, 50; Na-mercaptoacetate, 5 . Salt solutions (Snell et al. 1937) A and B, $0.5 \mathrm{ml}$. and $0.01 \mathrm{ml} . / 10 \mathrm{ml}$. respectively. Vitamins ( $\mu \mathrm{g}$. $10 \mathrm{ml}$.): biotin, $0 \cdot 005$; thiamine, $4 ; p$-aminobenzoic acid, $0 \cdot 1$.

Substances omitted from the incubation mixture

None

Vitamins

Glucose

Salts A (phosphates)

Salts $\mathbf{B}\left(\mathbf{M g}^{++}, \mathbf{M n}^{++}, \mathrm{Fe}^{+++}, \mathrm{Na}^{+}\right)$

Amino acids

Eight non-essential amino acids*

Tryptophan

Arginine

Valine

Threonine

Mercaptoacetate (aerobic conditions)
MLD $/ \mathrm{ml}$.

after $24 \mathrm{hr}$.

incubation

$2,500,000$

$2,500,000$

200,000

300,000

$1,750,000$

100,000

$2,200,000$

150,000

150,000

200,000

$2,200,000$

$2,500,000$

* Alanine, aspartic acid, glutamic acid, hydroxyproline, lysine, proline, serine, threonine. 
strated before noticeable lysis took place (Fig. 3). It appeared possible that the toxin molecule is synthesized within the organisms and is retained there until released by autolysis. In order to test this hypothesis disintegration of the organisms by sonic oscillation was used. Non-proliferating organisms were incubated in the complete medium (or with vitamins omitted), and samples were withdrawn at intervals; one portion was tested for toxicity without further treatment and another portion was centrifuged and the organisms,

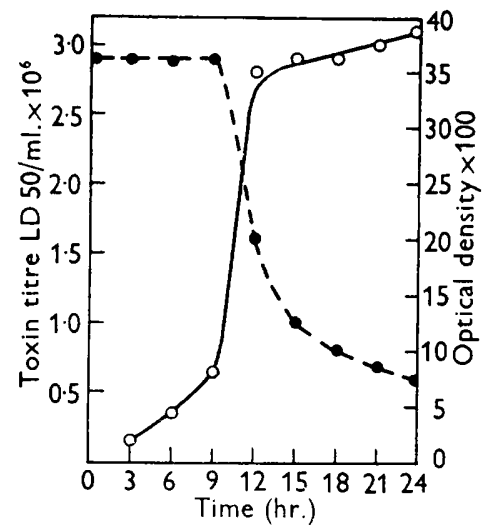

Fig. 3

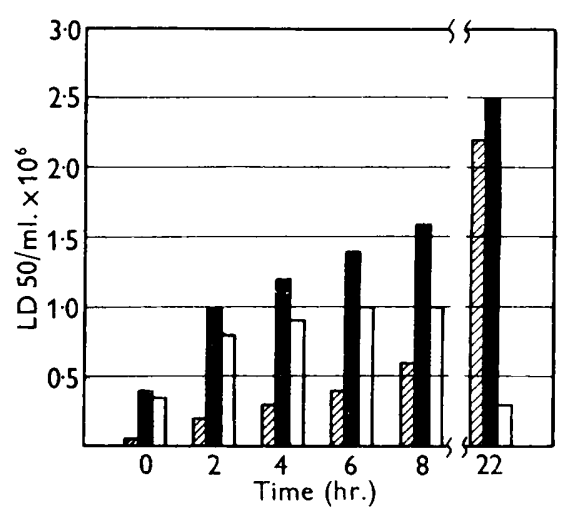

Fig. 4

Fig. 3. Correlation between autolysis and toxin production by non-proliferating cell suspensions of Clostridium parabotulinum type A (strain no. 2). $0-0$, toxin titse; - - - turbidity of suspensions (measured after dilution 1/5). Initial concentratio.1: $4 \times 10^{9}$ organisms $/ \mathrm{ml}$. Incubation medium (in $\mathrm{mg} . / 10 \mathrm{ml}$.): casamino acids (Difeo), 250, L-arginine, 30; DL-phenylalanine, 20; L-tryptophan, 5 ; L-tyrosine, 2.5 ; glucose, 50. Salts A (Snell et al. 1937), $1 \mathrm{ml}$. pH 7.2. Temperature of incubation $34^{\circ}$.

Fig. 4. Amounts of free and bound toxin as a function of incubation time. Suspension concentration: $3 \times 10^{9}$ organisms $/ \mathrm{ml}$. of Clostridium parabotulinum type A, strain no. 2 .

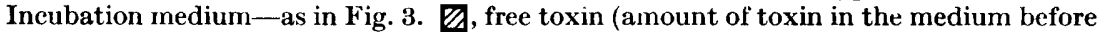
sonic disruption; $\square$, total toxin (amount of toxin in the medium after disruption of organisms by sonic oscillations); $\square$, cell-bound toxin (total toxin - free toxin).

after resuspension, were subjected to sonic disruption. Fig. 4 shows that appreciable amounts of toxin were found within washed organisms (toxin assayed after sonic disruption) immediately after resuspension (zero time). In the course of incubation, the amount of intracellular toxin rapidly increased and after $4 \mathrm{hr}$. a threefold increase was obtained, amounting to about $50 \%$ of the final amount of toxin obtained after $22 \mathrm{hr}$. of incubation. In other experiments (Kindler, Mager \& Grossowicz, 1955) even an eightfold increase was reached during a similar incubation period. 'The amount of 'free toxin' (spontaneously released into the medium) found in the untreated samples was only a small fraction of the total (i.e. cell-bound toxin +free toxin). On continued incubation (12-18 hr.) autolysis became pronounced and most of the toxin was set free. At this stage, as would be expected, sonic treatment increased only slightly the total yield of the toxin.

Toxin formation by cell-free preparations. Freshly harvested organisms were disrupted by sonic oscillation, the lysate added to the medium (as described for 
resting organisms) and incubated for $24 \mathrm{hr}$. at $34^{\circ}$. The growth of organisms which might have survived the sonic treatment, was eliminated by adding penicillin (10 units/ml.). Synthesis of toxin was not demonstrated under these conditions.

Inhibition of the toxin synthesis. In the hope of gaining more insight into the mechanism of toxin synthesis the effect of substances likely to interfere with biosynthetic processes was tested. The substances tested included various antibiotics, respiratory poisons and chelating agents. As can be seen from Table 4, addition of penicillin, even in amounts 1000-fold greater than that necessary for growth inhibition, had no effect on the toxin synthesis; no penicillinase was found in the suspension of organisms. However, streptomycin chloramphenicol, oxytetracycline and chlortetracycline at $100 \mu \mathrm{g} . / \mathrm{ml}$. inhibited toxin formation by about 50\%; growth was completely inhibited at $10 \mu \mathrm{g} . / \mathrm{ml}$. Other known metabolic inhibitors (arsenate, arsenite, dinitrophenol, azide) suppressed both growth and toxin synthesis at nearly the same concentrations.

Table 4. Effect of different compounds on growth and toxin production by Clostridium parabotulinum type A, strain no. 2

The growth medium was the CH medium (see Table 1).

\begin{tabular}{|c|c|c|c|}
\hline \multirow[b]{2}{*}{ Inhibitor added } & & \multicolumn{2}{|c|}{ Percentage inhibition of } \\
\hline & & Growth & $\begin{array}{c}\text { Toxin } \\
\text { production }\end{array}$ \\
\hline Penicillin 1000 units $/ \mathrm{ml}$. & & 100 & $\mathbf{0}$ \\
\hline Streptomycin & $100(\mu \mathrm{g} \cdot / \mathrm{ml})$. & 100 & 49 \\
\hline Chloramphenicol & $100(\mu \mathrm{g} . / \mathrm{ml})$. & 100 & 43 \\
\hline Chlortetracycline & $100(\mu \mathrm{g} . / \mathrm{ml})$. & 100 & 64 \\
\hline Oxytetracycline & $100(\mu \mathrm{g} . / \mathrm{ml})$. & 100 & 55 \\
\hline ED'TA (versene) & $1000(\mu \mathrm{g} \cdot / \mathrm{ml})$. & 100 & 100 \\
\hline EDTA (versene) & $100(\mu \mathrm{g} . / \mathrm{ml})$. & 0 & 90 \\
\hline EDTA $(100 \mu \mathrm{g} . / \mathrm{ml})+.\mathrm{Mg}^{++}$ & $400(\mu \mathrm{g} . / \mathrm{ml})$. & 0 & 10 \\
\hline Versene Fe-3 specific & $100(\mu \mathrm{g} . / \mathrm{ml})$. & 100 & 0 \\
\hline$\alpha, \alpha$-dipyridyl & $50(\mu \mathrm{g} . / \mathrm{ml})$. & 100 & $\mathbf{0}$ \\
\hline$o$-phenanthroline & $10(\mu \mathrm{g} \cdot / \mathrm{ml})$. & 100 & $\mathbf{0}$ \\
\hline 8-Hydroxyquinoline & $50(\mu \mathrm{g} . / \mathrm{ml})$. & 100 & 20 \\
\hline Na-arsenate & $\mathrm{M} / \mathbf{2 , 0 0 0}$ & 100 & 100 \\
\hline Na-arsenate & $M / 20,000$ & $\mathbf{0}$ & 0 \\
\hline Na-arsenite & $\mathbf{M} / \mathbf{5 0 0}$ & 100 & 100 \\
\hline Na-arsenite & $M / 5,000$ & 0 & 0 \\
\hline Na azide & $\mathrm{M} / 2,000$ & 0 & 0 \\
\hline 2,4-Uinitrophenol & $M / 5,000$ & 50 & $\mathbf{0}$ \\
\hline 2,4-Dinitrophenol & $M / 200,000$ & 0 & 0 \\
\hline
\end{tabular}

Ethylenediamine tetracetate (EDTA) at $100 \mu \mathrm{g} . / \mathrm{ml}$. suppressed almost completely toxin formation $(80-100 \%)$ without inhibiting growth. On the other hand, more specific iron complexing agents $(\alpha, \alpha$-dipyridyl, $o$-phenanthroline and versene $\mathrm{Fe}-3$ specific) had no effect on toxin synthesis at concentrations which completely inhibited growth. The effect of EDTA suggested that divalent cations may play a role in toxin synthesis. In fact, a mixture of divalent cations reversed completely the inhibition induced by EDTA. Further 
screening revealed magnesium ion as the active agent. Omission of $\mathbf{M g}^{++}$(from an EDTA-free medium) did not result, however, in a marked depression of toxin synthesis.

\section{DISCUSSION}

The results presented show that resting Clostridium parabotulinum type $\mathbf{A}$ synthesizes considerable amounts of toxin in a short period of time (4-8 hr.). Thus toxin formation can be studied independently of bacterial multiplication. Consideration may be given to the site of toxin formation. The fact that large amounts of toxin can be released from washed organisms by sonic disintegration provides evidence for the intracellular formation of the toxin. It appears, therefore, that accumulation of the toxin in the culture depends on an increased cell permeability of the organisms or autolysis. In this connexion it should be noted that only the extracellular ('free)' toxin is effective in vivo, whilst washed intact organisms (containing large amounts of 'bound' toxin) are practically non-toxic, although the amount of bound toxin present in the organisms may exceed the lethal dose by a factor of 5-10 (see, for instance, Fig. 4).

The following possibilities were considered to explain this phenomenon. (a) Sonic treatment activates the 'cell-bound' toxin by depolymerization (see Boroff, Raynaud \& Prévot, 1952; Wagman \& Bateman, 1953) or by some other alteration of the toxin molecule. (b) The 'bound' toxin forms, with some cell constituent, an inactive complex which may be broken up by autolysis or, artificially, by sonic treatment. $(c)$ The toxin within the organism is prevented from reaching the site of action by some unknown mechanism which operates in vivo. The first hypothesis seems least probable in view of the finding that toxin solutions are not affected by the sonic treatment. On the other hand the available data do not permit a choice between the other two possibilities. In connexion with hypothesis $(c)$, it may further be suggested that the toxin within the organisms is destroyed or inactivated in the host by the leucocytes. It will be recalled that according to van Ermengem (1897) and other investigators (Roemer, 1900; Landmann, 1904, quoted by Bengtson, 1924) Clostridium botulinum organisms, when injected intraperitoneally, undergo rapid phagocytosis. This explanation implies that the power of the white cells to cope with the 'bound' toxin is quite considerable. This interesting phenomenon, the details of which remain obscure, deserves further investigation.

In the system of non-multiplying organisms it was possible to determine certain of the essential factors which govern toxin production. The requirements for amino acids, glucose, inorganic phosphates and magnesium seem to indicate that conditions for de novo synthesis of protein must be satisfied. Rigorous proof for this claim might be provided by experiments involving labelled amino acids, However, the arrest of toxin production resulting from the omission of even a single essential amino acid (which the organism is unable to synthesize) strongly supports this assumption. Furthermore, the higher concentrations of amino acids required for optimal toxin production as compared with those necessary for multiplication, furnish additional evidence in favour of this hypothesis. 
The requirement for glucose suggests that a rich energy source is also essential for toxin synthesis. Likewise, the dependence on inorganic phosphate points to a need for energy rich compounds (e.g. adenosine triphosphate). The importance of adenosine triphosphate or related compounds for peptide bond synthesis as suggested by Lipmann (1949) was demonstrated by Peterson \& Greenberg (1952).

Although no need for magnesium ion could be demonstrated directly, the inhibition of toxin formation by EDTA and its specific reversal by magnesium ion indicates an essential function of this ion in the system described. It has been shown (Snoke, Yanari \& Bloch, 1953) that magnesium is needed for enzymic synthesis of glutathione. Whether additional factors (e.g. components of nucleic acids or vitamins) are involved in toxin synthesis cannot be answered at present in view of the difficulties inherent in removal from whole cells of substances not easily dissociable.

Rate of toxin formation. Little toxin is formed during the active period of multiplication. Since the toxin is formed intracellularly and since old organisms $(30-40 \mathrm{hr}$.) autolyse rapidly, it follows that most of the toxin is formed within a short period of time, early in the phase of decline. The kinetic studies with resting organisms (see Fig. 4) showed this very clearly. Our findings are in disagreement with observations of Raynaud, Turpin, Mangalo \& Bizzini (1954, 1955). These authors, using a different experimental set-up, concluded that the toxins of Clostridium botulinum and Corynebacterium diphtheriae are formed mainly during the logarithmic phase of growth. On the other hand, our observations are in accord with the findings of Pappenheimer (1955) that toxin production by $C$. diphtheriae starts only after cessation of the rapid-growth phase.

Autolysis results in the liberation of the cell contents into the surrounding medium. It is, however, not known whether the various enzymes liberated in this process are preserved or undergo destruction. Since neither autolysed nor artificially-disrupted organisms are able to synthesize toxin, it remains to be seen whether preservation of certain particulate cell components, or addition of soluble factors, is needed for toxin formation by a cell-free preparation.

Chloramphenicol and chlortetracycline were found to inhibit protein synthesis by resting staphylococci or cell fragments (Gale \& Folkes, 1953, 1955). The system studied by us was less sensitive to these agents and was not affected at all by penicillin. However, this difference in behaviour towards antibiotics does not necessarily indicate that there is a qualitative difference in the mechanism of protein synthesis in the different systems.

This paper forms part of a Ph.D. Thesis presented by S. H. Kindler to the Hebrew University, Jerusalem. The skilful technical assistance of Mrs Lea Glicks is gratefully acknowledged.

\section{REFERENCES}

Bengtson, I. A. (1924). Studies on organisms concerned as causative factors in botulism. Hyg. Lab. Bull. no. 136. Washington.

Boroff, D. A., Raynaud, M. \& Prévot, A. R. (1952). Studies of toxin of Clostridium botulinum, type D. J. Immunol. 68, 503. 
DACK, G. M. \& Woon, W. L. (1928). The mechanism of toxin production by Clostridium botulinum. J. infect. Dis. 42, 213.

van Ermengem, E. (1897). Contribution à l'étude des intoxication alimentaires. Recherches sur des accidents à caractères botuliniques provoqués par du jambon. Arch. pharmacodynamie, 3, 213, 499.

Gale, E. F. \& Folkes, J. P. (1953). The assimilation of amino acids by bacteria. 14. Nucleic acid and protein synthesis in Staphylococcus aureus. Biochem. J. 53, 483.

Gale, E. F. \& Folkes, J. P. (1955). The assimilation of amino acids by bacteria. 20. The incorporation of labelled amino acids by disrupted staphylococcal cells. Biochem. J. 59, 661.

Kindler, S. H., Mager, J. \& Grossowicz, N. (1955). Production of toxin by resting cells of $\mathrm{Cl}$. parabotulinum type A. Science, 122, 926.

Landmann, G. (1904). Úber die Ursache der Darmstadter Bohnenvergiftung. Hyg. Rdsch. 14, 449.

Lewis, K. H. \& Hill, E. V. (1947). Practical media and control measures for producing highly toxic cultures of Clostridium botulinum type A. J.Bact.53,213.

Lipmane, F. (1949). Mechanism of peptide bond formation. Fed. Proc. 8, 597.

Mager, J., Kindler, S. H. \& Grossowicz, N. (1954). Nutritional studies with Clostridium parabotulinum type A. J. gen. Microbiol. 10, 130.

Nelson, C. I. (1927). The relationship between the intracellular globulin and the toxin of C. botulinum. J. infect. Dis. 41, 9.

Pappenheimer, A. M., Jr. (1955). Pathogenesis of diphtheria. In Mechanisms of Microbial Pathogenicity. Symp. Soc. gen. Microbiol. 5, 43.

Peterson, E. A. \& Greenberg, D. M. (1952). Characteristics of the amino acidincorporating system of liver homogenates. J. biol. Chem. 194, 359.

RaynaUd, M. \& Second, L. (1949). Extraction des toxines botuliniques à partir des corps microbiens. Ann. Inst. Pasteur, 77, 316.

Raynaud, M., Turpin, A., Mangalo, R. \& Bizzini, R. (1954). Croissance et toxinogenese. Ann. Inst. Pasteur, 87, 599.

Raynaud, M., Turpin, A., Mangalo, R. \& Bizzini, R. (1955). Croissance et toxinogenese. Ann. Inst. Pasteur, 88, 24.

ReEd, L. J. \& Muench, M. (1938). A simple method of estimating fifty per cent endpoints. Amer. J. Hyg. 27, 493.

Rokmer, P. (1900). Ein Beitrag zur Ätiologie des Botulismus. Zbl. Bkt. (1. Abt.), $27,857$.

Stevenson, J. W., Helson, V. A. \& Reed, G. B. (1947). Preparation of Clostridium parabotulinum toxins. Canad. J. Res. E. 25, 14.

Snell, E. E., Strong, F. M. \& Peterson, W. H.(1937). Growth factors for bacteria. VI. Fractionation and properties of an accessory factor for lactic acid bacteria. Biochem. J. 31, 1789.

SNoke, J. E., YANARI, S. \& Bloch, K. (1953). Synthesis of glutathione from $\gamma$-glutamyl cysteine. J. biol. Chem. 201, 573.

Wagman, J. \& Bateman, J. B. (1953). Botulinum type A toxin; properties of a toxic dissociation product. Arch. Biochem. Biophys. 45, 375. 